\title{
Multifunctional Snake C-Type Lectins Affecting Platelets
}

\author{
Kenneth J. Clemetson Alexei Navdaev Dagmar Dörmann \\ Xiao-Yan Du Jeannine M. Clemetson \\ Theodor Kocher Institute, University of Berne, Switzerland
}

\section{Key Words}

Snake venom - C-type lectin · Platelet receptor $\cdot$ Binding sites $\cdot$ Mechanism

\begin{abstract}
Snake venoms contain a wide range of components, many of which affect haemostasis by activation or inhibition of platelets or coagulation factors. They can be classified into groups based on structure and mode of action. One group is the snake C-type lectins, so called because of the typical folding which closely resembles that found in classical Ctype lectins, such as selectins and mannosebinding proteins. Unlike the classic C-type lectins, those from snakes are generally heterodimeric with two subunits, $\alpha$ and $\beta$. Some are multimeric heterodimers. The subunits have homologous sequences and are generally linked by a disulphide bond as well as by swapping loops. One of the first C-type lectins with a defined function was echicetin
\end{abstract}

\begin{tabular}{ll}
\hline KARGER & ( ) 2002 S. Karger AG, Basel \\
Fax +4161306 1234-0147/01/0316-0148\$17.50/0 \\
$\begin{array}{l}\text { E-Mail karger@karger.ch } \\
\text { www.karger.com }\end{array}$ & $\begin{array}{l}\text { Accessible online at: } \\
\text { www.karger.com/journals/hae }\end{array}$
\end{tabular}

which was demonstrated to bind to platelet GPIb and block several functions of this receptor. Since then, many proteins with similar structure have been reported to act on platelet receptors or coagulation factors and several have been crystallized. These proteins were thought to be specific for a single platelet receptor or coagulation factor, i.e. they had only one receptor per heterodimer. Recent studies show that most of these Ctype lectins have binding sites for more than one ligand and have complex mechanisms of action.

Copyright $\odot 2002$ S. Karger AG, Basel

\section{Introduction}

Venoms produced by snakes have a wide variety of components which kill or weaken their preys. Venoms from some snake families contain mostly neurotoxic proteins, while others such as those of the Viperidae and Cro-
Dr. K.J. Clemetson

Theodor Kocher Institute, University of Berne

Freiestrasse 1, CH-3012 Berne (Switzerland)

Tel. +41 3163141 48, Fax +41 319215443

E-Mail clemetson@tki.unibe.ch 
talidae are mainly haemorrhagic. Snake Ctype lectins are an important class among the protein family that has been shown to have haemorrhagic effects. This family is named after the type of folding that occurs in classic C-type lectins, such as mannose-binding protein $[1,2]$ and the selectins [3]. The ' $\mathrm{C}$ ' is from calcium-dependent and the 'lectin' from the sugar-binding function but, in fact, most of the snake C-type lectins do not show these properties and the calcium-binding loop is deleted in their structure. We have nevertheless retained this nomenclature since it is that of the primary literature. C-type lectins were first identified as part of metalloprotease/disintegrin/C-type lectin structures without any specific function. A large number of snake Ctype lectins have now been characterized with effects on either coagulation factors or platelets. Those affecting platelets either inhibit or activate them by binding to specific receptors like GPIb, $\alpha_{2} \beta_{1}$, and GPVI.

\section{Snake C-Type Lectin Targets}

C-type lectins that act via GPIb to agglutinate platelets include alboaggregins [4-6], flavocetins $A$ and $B$ [7] and mamushigin [8]. Most of the inhibitory C-type lectins described so far bind to GPIb. These include echicetin [9], jararaca GPIb binding protein $[10,11]$, tokaricetin [12], CHH-A and B [4], and agkicetin [13]. Echicetin, a heterodimeric snake C-type lectin from Echis carinatus, has been shown by several authors to bind specifically to platelet GPIb and to block platelet interactions with von Willebrand factor ( $\mathrm{vWf}$ ) [9] and thrombin [14]. There has been considerable interest in using C-type lectins such as echicetin as antithrombotics, blocking the interaction between vWf and platelets. However, when echicetin or similar snake C-type lectins were injected into small animals to study their effects in vivo, induction of thrombocytopenia has often been reported [9, 15]. Generally, the platelet count dropped to $20-30 \%$ of the control value and then gradually recovered over several hours. This phenomenon has remained unexplained. Other snake C-type lectins bind to different platelet receptors, for example, convulxin, a trimeric heterodimer, has been shown to be specific for GPVI [16]. Several other snake C-type lectins were reported to bind to other platelet receptors, aggretin (or rhodocytin) [17] and rhodocetin [18], from Calloselasma rhodostoma venom and EMS16, a C-lectin type protein from Echis multisquamatus venom [19] were shown to interact with $\alpha_{2} \beta_{1}$, and, in the case of aggretin (or rhodocytin) with GPIb and possibly with (an)other receptor(s), which has not yet been identified. Rhodocetin was also the first example described of a snake C-type lectin where the subunits associate noncovalently and there is no disulphide bond between them. This might allow more rapid evolution by enabling subunits to exchange more rapidly. A wide range of other snake C-type lectins has been described that activate coagulation factors or affect other plasma components involved in hemostasis. These include factor IX/factor $\mathrm{X}$ binding proteins from Trimeresurus flavoviridis [20] and Echis carinatus leucogaster [21] venom and coagulation factor $\mathrm{X}$ binding protein from Deinagkistrodon acutus venom [22].

Bothrojaracin, is a $27 \mathrm{kD}$ C-type lectin from Bothrops jararaca venom which has been characterized as a potent thrombin inhibitor [23]. Bothrojaracin binds to exosites I and II, with a dissociation constant of $0.7 \mathrm{n} M$, and influences but does not block the proteinase catalytic site. Bothrojaracin also binds the partially exposed anion-binding exosite (proexosite I) of prothrombin and blocks its activation to thrombin [24]. 
Botrocetin forms a bimolecular complex with vWF that is capable of binding specifically to GPIba, a component of the GPIb-IX$\mathrm{V}$ complex on the platelet membrane [25]. The venoms of several snake species in the genus Bothrops and at least one species in the genus Bitis contain an activity with the properties ascribed to botrocetin, but detailed studies have been conducted mostly with the protein isolated from B. jararaca.

Bitiscetin from Bitis arietans venom [26] forms a bimolecular complex with vWF, like botrocetin; however the binding site of bitiscetin is within the A3 domain [27]. Binding also involves the GPIb-binding site of vWF located on the A1 domain because it was inhibited by a monoclonal antibody to vWF whose epitopes are within this domain and that block binding of vWF to platelets induced by ristocetin or botrocetin.

\section{Ligand Binding Sites}

After the characterization of the first few snake C-type lectins it was generally assumed that the $\alpha$ - and $\beta$-subunits had separate functions, and several studies supported this conclusion. It is difficult to compare the positive and negative results from such studies because the individual subunits were prepared under a wide variety of conditions. It nevertheless seems plausible that the subunits prepared, after separation under reducing conditions, can refold if the thiol groups are not blocked, to give at least partially active structures. Under these conditions, several authors were able to show that $\alpha$ - and $\beta$-subunits had different binding characteristics [28]. However, the first determination of the X-ray crystal structure of a snake C-type lectin by Mizuno et al. [29] indicated that the two subunits were more tightly associated than had previously been suspected and dem- onstrated the formation of a concave surface formed by loop-swapping between the two subunits as most likely the binding site for the ligand. This was substantiated by a recent study from the same group showing that the binding site for the Gla domain of factor $\mathrm{X}$ does indeed lie in this region between the two subunits of the factor $\mathrm{X}$ binding protein [30]. Thus, the consensus of opinion moved to a model where snake C-type lectins have essentially one binding site made up of parts of both subunits.

While this model could be valid for some snake C-type lectin interactions with single ligands, it soon became clear that this is not always the case and, in fact, more complex situations may be commoner. One of the first examples of a C-type lectin interacting with two different ligands was echicetin [31]. As mentioned above, echicetin was one of the first snake C-type lectins interacting with platelet receptors to be identified and characterized. It was shown to interact with GPIb and to inhibit GPIb-related platelet functions [9]. Since then C-type lectins with similar properties were identified in a variety of species of snakes $[4,10,13,32]$. The first indication that echicetin binds to components other than GPIb came from the observation that echicetin induced platelet agglutination in platelet-rich plasma but not with washed platelets. This suggested that there is a component in plasma that is recognized by echicetin and can cross-link echicetin bound to GPIb to link platelets together. Indeed, this component was identified as a subgroup of IgM $\kappa$ and can be used to affinity-purify echicetin [31]. The results from earlier studies with isolated subunits suggest that the $\beta$-subunit is probably involved in binding to GPIb which might indicate (from steric considerations alone) that the $\alpha$-subunit is mainly involved in binding IgM $\kappa$. 
Another example of a snake C-type lectin that binds to more than one ligand is alboaggregin A [4, 33-35]. The situation is slightly more complicated here because this is a dimeric heterodimer or tetramer and probably binding sites are present on both heterodimers. Alboaggregin A was first identified as a GPIb-binding protein from Trimeresurus albolabris venom as well as alboaggregins $\mathrm{B}$ and $\mathrm{C}$ [33]. However, unlike the two others it showed much stronger activating effects on platelets. At first this was ascribed to the tetrameric structure, whereas alboaggregin B is simply heterodimeric, leading to more clustering of receptors and hence a stronger signal $[4,34]$. However, the fact that the tyrosine phosphorylation pattern in platelets activated by alboaggregin A was different from that in platelets activated by alboaggregin B pointed to the involvement of other receptors. Investigation of the platelet receptors which alboaggregin A binds to clarified this issue by showing that not only GPIb but also GPVI is involved [35, 36]. Activation of platelets by clustering GPVI is well known as the mechanism used by collagen, collagen-related peptides and convulxin, also a snake C-type lectin. It is intriguing that of the four chains making up alboaggregin A, presumably two $\alpha$ (AlboA chains 1 and 2)- and two $\beta$ (AlboA chains 3 and 4)-chains, two have sequences that resemble the $\alpha$ - and $\beta$-subunits of convulxin ( 2 and 4 ) whereas the other two (1 and 3) more closely resemble $\alpha$ - and $\beta$-subunits of C-type lectins that interact with GPIb [6].

Another example of a C-type lectin with multiple ligands is aggretin (or rhodocytin) $[17,37]$. This was originally reported to be $\alpha_{2} \beta_{1}$-specific and not to interact with GPIb $[17,37]$. Later studies indicated that both $\alpha_{2} \beta_{1}$ and GPIb but not GPVI were involved [38, 39]. On the other hand, platelets genetically lacking $\alpha_{2} \beta_{1}$, where GPIb was also removed proteolytically, still showed the same reactivi- ty with this C-type lectin, suggesting that yet another receptor played a critical role [40].

There are other examples of C-type lectins which were thought to have a simple monovalent activity, but which now appear more complex. A classic example of these is botrocetin, mentioned above. This was thought to cause vWf to bind to GPIb by binding to the A1 domain and changing its configuration to an 'activated' state. More recent work based upon X-ray crystallographic structure determination [41] indicates that this may not be the whole story and that following initial binding between botrocetin/A1 domain and GPIb, botrocetin also engages a second binding site with GPIb and so may link vWf and GPIb together physically.

In the case of bothrojaracin, it is also not clear whether only one binding site is adequate to inhibit both the exosites on thrombin or, again, if two independent bind sites on the C-type lectin are necessary [42]. In order to elucidate this and other problems of C-type lectin-binding sites it will be necessary to have more structural information based on X-ray crystallographic data.

\section{Structure-Function Relationships}

Modelling the structure of snake C-type lectins has been a fairly useful approach to establishing putative binding sites on their surfaces based on the premise that interactions with ligands involve electrostatic as well as shape-matching interactions. Comparison of linear sequence data is not always a very helpful indication of similarities in binding ligands for the simple reason that even where ligands are shared between two C-type lectins, for example, from different snake species, it does not mean that the binding site on the ligand is identical. Species differences between the sequence and structure of the target 
ligand also need to be considered. If the two snake species have a different distribution of prey species then evolution will optimize Ctype lectin/prey ligand interactions for those sequences which are most encountered or which offer the snake the best prey mass/ venom protein relationship. Analysis of this situation is complicated by the fact that it is the whole venom that is optimized by evolution and not just the single molecular species but the principle holds nevertheless. Why does one venom contain a number of components, including C-type lectins which can bind to the same ligand and may indeed compete for binding sites? A plausible answer is that again we are dealing with a kind of combinatory library that is being screened constantly by another library, namely the molecules present in the various prey species. Venom components interact with a wide variety of other cells, endothelial cells, smooth muscle cells, nerve cells, and not only with plasma proteins or platelets in blood, despite these being prime targets. Even if specific components may appear to compete when tested against platelets, they may have individual advantages against other cells in particular prey species.
There are a variety of C-type lectins which are generally considered to interact with a single platelet ligand. A typical example is convulxin, thought to be specific for GPVI. However, even in this case a number of questions can be asked. One of these is whether convulxin has two different binding sites for GPVI with different affinities [43]. An additional possibility is that convulxin has (a) binding site(s) for other convulxin molecules [44]. Whether these are always present or are exposed after binding to GPVI are additional questions that have not been clearly resolved. It may be optimal in terms of amount of venom to attain maximum platelet activation to deliver (or assemble) a few large multimeric structures to the platelet surface rather than a larger number of smaller multimers. These questions can only be addressed by a physicochemical approach when recombinant C-type lectin molecules with systematically mutated binding sites become available.

\section{Acknowledgement}

Work at the Theodor Kocher Institute was supported by grants from the Swiss National Science Foundation No. 31-52396.97 and 31-063868.00 to K.J.C.

\section{References}

1 Weis WI, Kahn R, Fourme R, Drickamer K, Hendrickson WA: Structure of the calcium-dependent lectin domain from a rat mannosebinding protein determined by MAD phasing. Science 1991;254: 1608-1615.

2 Weis WI, Drickamer K, Hendrickson WA: Structure of a C-type mannose-binding protein complexed with an oligosaccharide. Nature 1992;360:127-134.
3 Chou KC: Knowledge-based model building of the tertiary structures for lectin domains of the selectin family. J Protein Chem 1996;15:161168.

4 Andrews RK, Kroll MH, Ward CM, Rose JW, Scarborough RM, Smith AI, Lopez JA, Berndt MC: Binding of a novel 50-kilodalton alboaggregin from Trimeresurus albolabris and related viper venom proteins to the platelet membrane glycoprotein Ib-IX-V complex. Effect on platelet aggregation and glycoprotein Ib-mediated platelet activation. Biochemistry 1996;35:12629-12639.
5 Peng M, Lu W, Kirby EP: Alboaggregin-B: A new platelet agonist that binds to platelet membrane glycoprotein Ib. Biochemistry 1991;30: 11529-11536.

6 Kowalska MA, Tan L, Holt JC, Peng M, Karczewski J, Calvete JJ, Niewiarowski S: Alboaggregins A and B. Structure and interaction with human platelets. Thromb Haemost 1998;79:609-613. 
7 Taniuchi Y, Kawasaki T, Fujimura Y, Suzuki M, Titani K, Sakai Y, Kaku S, Hisamichi N, Satoh N, Takenaka T, et al: Flavocetin-A and -B, two high molecular mass glycoprotein $\mathrm{Ib}$ binding proteins with high affinity purified from Trimeresurus flavoviridis venom, inhibit platelet aggregation at high shear stress. Biochim Biophys Acta 1995;1244:331338.

8 Sakurai Y, Fujimura Y, Kokubo T, Imamura K, Kawasaki T, Handa M, Suzuki M, Matsui T, Titani K, Yoshioka A: The cDNA cloning and molecular characterization of a snake venom platelet glycoprotein Ib-binding protein, mamushigin, from Agkistrodon halys blomhoffii venom. Thromb Haemost 1998;79: 1199-1207.

9 Peng M, Lu W, Beviglia L, Niewiarowski S, Kirby EP: Echicetin: A snake venom protein that inhibits binding of von Willebrand factor and alboaggregins to platelet glycoprotein Ib. Blood 1993;81:23212328.

10 Fujimura Y, Ikeda Y, Miura S, Yoshida E, Shima H, Nishida S, Suzuki M, Titani K, Taniuchi Y, Kawasaki $\mathrm{T}$ : Isolation and characterization of jararaca GPIb-BP, a snake venom antagonist specific to platelet glycoprotein Ib. Thromb Haemost 1995; 74:743-750.

11 Kawasaki T, Fujimura Y, Usami Y, Suzuki M, Miura S, Sakurai Y, Makita K, Taniuchi Y, Hirano K, Titani K: Complete amino acid sequence and identification of the platelet glycoprotein Ib-binding site of jararaca GPIb-BP, a snake venom protein isolated from Bothrops jararaca. J Biol Chem 1996;271:1063510639.

12 Kawasaki T, Taniuchi Y, Hisamichi N, Fujimura Y, Suzuki M, Titani K, Sakai Y, Kaku S, Satoh N, Takenaka $\mathrm{T}$, et al: Tokaracetin, a new platelet antagonist that binds to platelet glycoprotein ib and inhibits von Willebrand factor-dependent shear-induced platelet aggregation. Biochem J 1995;308:947-953.

13 Chen YL, Tsai IH: Functional and sequence characterization of agkicetin, a new glycoprotein Ib antagonist isolated from Agkistrodon acutus venom. Biochem Biophys Res Commun 1995;210:472-477.
14 Peng M, Emig FA, Mao A, Lu W, Kirby EP, Niewiarowski S, Kowalska MA: Interaction of echicetin with a high affinity thrombin binding site on platelet glycoprotein GPIb. Thromb Haemost 1995;74:954957.

15 Fujimura Y, Kawasaki T, Titani K: Snake venom proteins modulating the interaction between von Willebrand factor and platelet glycoprotein Ib. Thromb Haemost 1996;76: 633-639.

16 Polgar J, Clemetson JM, Kehrel BE, Wiedemann M, Magnenat EM, Wells TNC, Clemetson KJ: Platelet activation and signal transduction by convulxin, a C-type lectin from Crotalus durissus terrificus (tropical rattlesnake) venom via the p62/ GPVI collagen receptor. J Biol Chem 1997;272:13576-13583.

17 Huang TF, Liu CZ, Yang SH: Aggretin, a novel platelet-aggregation inducer from snake (Calloselasma rhodostoma) venom, activates phospholipase $\mathrm{C}$ by acting as a glycoprotein Ia/IIa agonist. Biochem J 1995; 309:1021-1027.

18 Wang R, Kini RM, Chung MC: Rhodocetin, a novel platelet aggregation inhibitor from the venom of Calloselasma rhodostoma (Malayan pit viper): Synergistic and noncovalent interaction between its subunits. Biochemistry 1999;38:75847593.

19 Marcinkiewicz C, Lobb RR, Marcinkiewicz MM, Daniel JL, Smith $\mathrm{JB}$, Dangelmaier C, Weinreb PH, Beacham DA, Niewiarowski S: Isolation and characterization of EMS16, a C-lectin type protein from Echis multisquamatus venom, a potent and selective inhibitor of the alpha2beta1 integrin. Biochemistry 2000;39:9859-9867.

20 Matsuzaki R, Yoshiara E, Yamada M, Shima K, Atoda H, Morita T: cDNA cloning of IX/X-Bp, a heterogeneous two-chain anticoagulant protein from snake venom. Biochem Biophys Res Commun 1996;220: 382-387.

21 Chen YL, Tsai IH: Functional and sequence characterization of coagulation factor IX/factor X-binding protein from the venom of Echis carinatus leucogaster. Biochemistry 1996;35:5264-5271.
22 Atoda $\mathrm{H}$, Ishikawa $\mathrm{M}$, Mizuno $\mathrm{H}$, Morita T: Coagulation factor Xbinding protein from Deinagkistrodon acutus venom is a Gla domainbinding protein. Biochemistry 1998 ; 37:17361-17370.

23 Zingali RB, Jandrot-Perrus M, Guillin M-C, Bon C: Bothrojaracin, a new thrombin inhibitor isolated from Bothrops jararaca venom: Characterization and mechanism of thrombin inhibition. Biochemistry 1993;32:10794-10802.

24 Monteiro RQ, Zingali RB: Inhibition of prothrombin activation by bothrojaracin, a C-type lectin from Bothrops jararaca venom. Arch Biochem Biophys 2000;382:123-128.

25 Read MS, Smith SV, Lamb MA, Brinkhous KM: Role of botrocetin in platelet agglutination: Formation of an activated complex of botrocetin and von Willebrand factor. Blood 1989;74:1031-1035.

26 Hamako J, Matsui T, Suzuki M, Ito M, Makita K, Fujimura Y, Ozeki Y, Titani K: Purification and characterization of bitiscetin, a novel von Willebrand factor modulator protein from Bitis arietans snake venom. Biochem Biophys Res Commun 1996;226:273-279.

27 Obert B, Houllier A, Meyer D, Girma JP: Conformational changes in the A3 domain of von Willebrand factor modulate the interaction of the A1 domain with platelet glycoprotein Ib. Blood 1999;93:1959-1968.

28 Peng M, Holt JC, Niewiarowski S: Isolation, characterization and amino acid sequence of echicetin beta subunit, a specific inhibitor of von Willebrand factor and thrombin interaction with glycoprotein Ib. Biochem Biophys Res Commun 1994; 205:68-72.

29 Mizuno H, Fujimoto Z, Koizumi M, Kano H, Atoda H, Morita T: Crystal structure of coagulation factor IXbinding protein from habu snake venom at $2.6 \AA$ : Implication of central loop swapping based on deletion in the linker region. J Mol Biol 1999; 289:103-112.

30 Mizuno H, Fujimoto Z, Atoda $\mathrm{H}$, Morita T: Crystal structure of an anticoagulant protein in complex with the Gla domain of factor X. Proc Natl Acad Sci USA 2001;98:72307234. 
31 Navdaev A, Dormann D, Clemetson JM, Clemetson KJ: Echicetin, a GPIb-binding snake C-type lectin from Echis carinatus, also contains a binding site for IgMkappa responsible for platelet agglutination in plasma and inducing signal transduction. Blood 2001;97:2333-2341.

32 Chen YL, Tsai KW, Chang T, Hong TM, Tsai IH: Glycoprotein Ib-binding protein from the venom of Deinagkistrodon acutus-cDNA sequence, functional characterization, and three-dimensional modeling. Thromb Haemost 2000;83:119126.

33 Peng M, Lu W, Kirby EP: Characterization of three alboaggregins purified from Trimeresurus albolabris venom. Thromb Haemost 1992;67: 702-707.

34 Falati S, Edmead CE, Poole AW: Glycoprotein Ib-V-IX, a receptor for von Willebrand factor, couples physically and functionally to the $\mathrm{Fc}$ receptor gamma-chain, Fyn, and Lyn to activate human platelets. Blood 1999;94:1648-1656.

35 Dormann D, Clemetson JM, Navdaev A, Kehrel BE, Clemetson KJ: Alboaggregin A activates platelets by a mechanism involving glycoprotein VI as well as glycoprotein Ib. Blood 2001;97:929-936.
36 Asazuma N, Marshall SJ, Berlanga O, Snell D, Poole AW, Berndt MC, Andrews RK, Watson SP: The snake venom toxin alboaggregin-A activates glycoprotein VI. Blood 2001; 97:3989-3991.

37 Shin Y, Morita T: Rhodocytin, a functional novel platelet agonist belonging to the heterodimeric C-type lectin family, induces platelet aggregation independently of glycoprotein Ib. Biochem Biophys Res Commun 1998;245:741-745.

38 Navdaev A, Clemetson JM, Polgar J, Kehrel BE, Glauner M, Magnenat E, Wells TN, Clemetson KJ: Aggretin, a heterodimeric C-type lectin from Calloselasma rhodostoma (Malayan pit viper) stimulates platelets by binding to $\alpha 2 \beta 1$ integrin and GPIb, activating Syk and PLC $\gamma 2$, but does not involve the GPVI/Fc $\gamma$ collagen receptor. $\mathrm{J}$ Biol Chem 2001;276:20882-20889.

39 Chung $\mathrm{CH}$, Peng HC, Huang TF: Aggretin, a C-type lectin protein, induces platelet aggregation via integrin alpha(2)beta(1) and GPIb in a phosphatidylinositol 3-kinase independent pathway. Biochem Biophys Res Commun 2001;285:689-695.
40 Bergmeier W, Bouvard D, Eble JA, Mokhtari-Nejad R, Schulte V, Zirngibl H, Brakebusch C, Fassler R, Nieswandt B: Rhodocytin (aggretin) activates platelets lacking $\alpha 2 \beta 1$ integrin, GPVI, and the ligand binding domain of GPIba. J Biol Chem 2001;276:25121-25126.

41 Sen U, Vasudevan S, Subbarao G, McClintock RA, Celikel R, Ruggeri ZM, Varughese KI: Crystal structure of the von Willebrand factor modulator botrocetin. Biochemistry 2001;40:345-352.

42 Arocas V, Zingali RB, Guillin MC, Bon C, Jandrot-Perrus M: Bothrojaracin: A potent two-site-directed thrombin inhibitor. Biochemistry 1996;35:9083-9089.

43 Niedergang F, Alcover A, Knight CG, Farndale RW, Barnes MJ, Francischetti IM, Bon C, Leduc M: Convulxin binding to platelet receptor GPVI: Competition with collagen related peptides. Biochem Biophys Res Commun 2000;273:246250.

44 Marlas G: Purification and preliminary structure of a potent platelet aggregating glycoprotein isolated from the venom of Crotalus durissus cascavella. Toxicon 1982;20:289290. 